\title{
Absorbable and nonabsorbable packing after functional endoscopic sinus surgery: systematic review and meta-analysis of outcomes
}

\author{
Tang-Chuan Wang $\cdot$ Chih-Jaan Tai $\cdot$ Yung-An Tsou \\ Li-Tai Tsai $\cdot$ Yu-Fen Li $\cdot$ Ming-Hsui Tsai
}

Received: 6 February 2014 / Accepted: 15 May 2014 / Published online: 14 June 2014

(c) The Author(s) 2014. This article is published with open access at Springerlink.com

\begin{abstract}
The purpose of the study was to perform a systematic review and meta-analysis of the literature to compare the efficacy (and other postoperative outcomes) of nonabsorbable versus absorbable nasal packing after functional endoscopic sinus surgery (FESS) for the treatment of chronic rhinosinusitis. Studies were considered for inclusion if they were published in English language, were randomized clinical trials, and reported on outcomes following postoperative synechia. The primary outcome for meta-analysis was the incidence of postoperative synechia; pooled odds ratios (ORs) and $95 \%$ confidence intervals (CIs) were calculated using fixed-effects models. Five studies, involving 241 nasal cavities in each treatment group, were included in the systematic review. The prevalence of synechia ranged from 4.6 to $8.0 \%$ in the absorbable groups and from 8.0 to $35.7 \%$ in the nonabsorbable groups. Postoperative bleeding was lower in the absorbable groups, whereas there was no clear finding regarding postoperative pain. Postoperative edema was generally similar between groups. There were no consistent findings regarding
\end{abstract}

T.-C. Wang · C.-J. Tai $(\bowtie) \cdot$ Y.-A. Tsou $\cdot$ L.-T. Tsai · M.-H. Tsai Department of Otolaryngology, China Medical University Hospital, Taichung, Taiwan

e-mail: d12493@mail.cmuh.org.tw; edsam@seed.net.tw

T.-C. Wang

Department of Otolaryngology-Head and Neck Surgery,

University of Iowa, Iowa City, IA, USA

T.-C. Wang · C.-J. Tai · Y.-A. Tsou · L.-T. Tsai · M.-H. Tsai Department of Medicine, China Medical University, Taichung, Taiwan

Y.-F. Li

Graduate Institute of Biostatistics, China Medical University,

Taichung, Taiwan bleeding and pain on packing removal. Two studies using the same type of packing material were included in the meta-analysis. The combined OR $(0.33,95 \%$ CI 0.04 2.78) for postoperative synechia did not significantly favor $(P=0.308)$ absorbable packing over nonabsorbable packing. Although there is some evidence in the available literature that absorbable nasal packing may provide superior outcomes to nonabsorbable packing after FESS, the lack of homogeneity between studies makes definitive conclusions impossible. Further randomized clinical trials are needed to compare the efficacy of different types of absorbable nasal packing for preventing synechia after FESS.

Keywords Absorbable $\cdot$ Efficacy $\cdot$ Epistaxis $\cdot$ FESS · Functional endoscopic sinus surgery $\cdot$ Meta-analysis · Nasal $\cdot$ Nonabsorbable $\cdot$ Packing $\cdot$ Synechia

\section{Introduction}

Chronic rhinosinusitis is an extremely common condition, affecting millions of individuals the world over. Indeed, reports suggest that up to approximately $16 \%$ of the adult population in the USA suffer from this condition [1,2]. As chronic rhinosinusitis can have a significant negative impact on quality of life [3], treatment is typically required. In most cases, chronic rhinosinusitis can be managed through pharmacologic means; however, some individuals do not respond to such intervention and require surgery [2].

Functional endoscopic sinus surgery (FESS) is perhaps the most commonly used surgical approach for managing chronic rhinosinusitis $[4,5]$ and aims to improve/ restore drainage and airflow throughout affected sinuses [2]. Although FESS is effective in more than $90 \%$ of patients [6] and significantly improves quality of life [7], 
postoperative complications, in particular bleeding and adhesions (synechia), are not uncommon [8]. As a consequence, the nasal cavity is often packed after FESS with material designed to stem any ongoing bleeding, reduce clot formation, ameliorate the risk of synechia, and promote healing [8, 9]. Traditionally, nonabsorbable nasal packing has been applied after FESS [7]; however, such packing, and subsequent removal, is not well tolerated by patients [10]. More recently, absorbable nasal packing has been introduced and appears to be well tolerated by patients $[11,12]$.

Although a number of studies have compared the efficacy of nonabsorbable and absorbable nasal packing after FESS [8-14], there is conflicting evidence between studies as to whether one method is superior to the other or whether the methods have comparable efficacy. Therefore, we performed a systematic review and meta-analysis of the available literature in an effort to gain a better understanding of the efficacy and other outcomes concerning nonabsorbable versus absorbable nasal packing after FESS for the treatment of chronic rhinosinusitis. We included randomized trials only and examined synechia in our metaanalysis as a key indicator of nasal packing efficacy.

\section{Materials and methods}

Search strategy

MEDLINE, Current Contents, and the Cochrane databases were searched on January 31, 2013, using combinations of the following search terms: FESS, rhinosinusitis, bleeding, gelatin, hyaluronic acid, carboxymethylated cellulose (CMC), and packing.

Selection of studies

Studies were considered for inclusion in the systematic review and meta-analysis if they were available in English, were randomized clinical trials, and reported on postoperative pain, edema, synechia/adhesion, and/or bleeding/ hemostasis as study outcomes. Studies that did not meet these criteria were excluded.

\section{Data extraction}

Data were extracted by two independent reviewers who consulted with a third reviewer, as necessary, to resolve any disagreements. For each eligible study, the following information and data were extracted: authors, year of publication, number of nasal cavities packed per treatment group, age of participants, sex distribution of participants, the type of nasal packing used, postoperative treatment, the time to removal of packing, the incidence of postoperative synechia, the incidence of postoperative bleeding, postoperative pain, postoperative edema, and bleeding and pain on removal of packing.

The primary outcome for meta-analysis was the incidence of postoperative synechia for absorbable versus nonabsorbable nasal packing.

Data analysis

Odds ratios (ORs) with $95 \%$ confidence intervals (CIs) were calculated for binary outcomes and comparisons made for absorbable versus nonabsorbable nasal packing. A $\chi^{2}$-based test of homogeneity was carried out, and the inconsistency index $\left(I^{2}\right)$ statistic was determined. If $I^{2}$ was $>50 \%$ or $>75 \%$, the studies were considered to be heterogeneous or highly heterogeneous, respectively. If $I^{2}$ was $<25 \%$, the studies were considered to be homogeneous. If the $I^{2}$ statistic $(>50 \%)$ indicated heterogeneity existed between studies, a random-effects model was calculated. Otherwise, a fixed-effects model was calculated. Pooled summary statistics for ORs of the individual studies are reported. A $P$ value $<0.05$ was taken to indicate statistical significance. All analyses were performed using Comprehensive Meta-Analysis statistical software, version 2.0 (Biostat, Englewood, NJ).

\section{Results}

Literature search

A total of 124 records were retrieved in the database search (Fig. 1). Of these, 106 were excluded after title/abstract review, 13 were excluded after full-text review, and five were included in the systematic review (two of these studies were also included in the meta-analysis of postoperative synechia).

Study characteristics

The characteristics of the studies [8, 11-13, 15] included in the systematic review are summarized in Table 1 . The number of nasal cavities treated in each study ranged from 30 to 100 with a total of 241 nasal cavities treated in each group for all studies combined. The age of study participants was reported in four of the five studies [8, 11, 13, 15] and was generally similar among these studies, ranging from 35.7 to 43.2 years among three studies $[8,13,15]$ and 54.0 years in one study [11]. The sex distribution of participants was also reported in the same four studies [8, 11, 13, 15], with the proportion of males ranging from 54 to $67 \%$. Regarding absorbable nasal packing materials, MeroGel ${ }^{\circledR}$ was used in two studies [8, 12], while Cutanplast [15], CMC foam [13], 
Fig. 1 Flow diagram of study selection

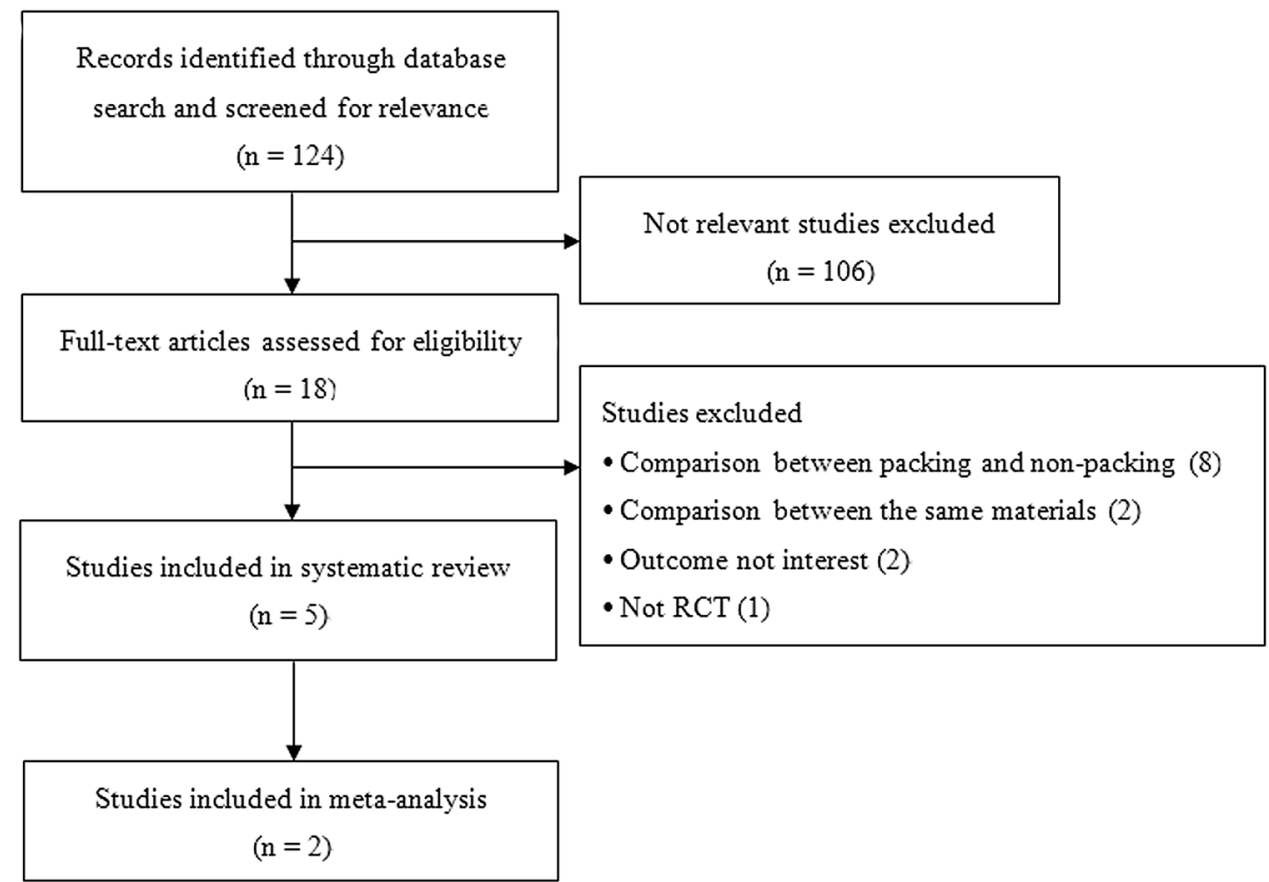

Table 1 Characteristics of studies included in the systematic review

\begin{tabular}{|c|c|c|c|c|c|c|c|}
\hline References & $\begin{array}{l}\text { Nasal cavities } \\
\text { packed, abs } \\
\text { versus nonabs }\end{array}$ & $\begin{array}{l}\text { Age } \\
\text { (years) }\end{array}$ & $\begin{array}{l}\text { Sex } \\
(\text { male \%) }\end{array}$ & $\begin{array}{l}\text { Absorbable } \\
\text { packing }\end{array}$ & $\begin{array}{l}\text { Nonabsorbable } \\
\text { packing }\end{array}$ & $\begin{array}{l}\text { Postoperative } \\
\text { treatment }\end{array}$ & $\begin{array}{l}\text { Time to packing } \\
\text { removal }\end{array}$ \\
\hline Cho et al. [15] & 100 versus 100 & 35.7 & 64 & Cutanplast & Merocel & $\begin{array}{l}\text { Second-generation } \\
\text { cephalosporin or } \\
\text { clarithromycin, } \\
\text { analgesics as } \\
\text { needed, prednisone }\end{array}$ & NA \\
\hline Miller et al. [8] & 37 versus 37 & 39.1 & 54 & MeroGel $^{\circledR}$ & Merocel & $\begin{array}{l}\text { Cefuroxime, saline } \\
\text { nasal spray and } \\
\text { nasal irrigation }\end{array}$ & $\begin{array}{l}\text { Postoperative } \\
\text { day } 5-7\end{array}$ \\
\hline Berlucchi et al. [12] & 44 versus 44 & NA & NA & MeroGel $^{\circledR}$ & PVA sponge & $\begin{array}{l}\text { Amoxicillin + cla- } \\
\text { vulanic acid, non- } \\
\text { aspirin analgesics } \\
\text { as needed, saline } \\
\text { nasal spray }\end{array}$ & NA \\
\hline Szczygielski et al. [13] & 30 versus 30 & 43.2 & 62 & CMC foam & Routine packing ${ }^{\mathrm{a}}$ & $\begin{array}{l}\text { Cefazolin sodium, } \\
\text { decongestants }\end{array}$ & $\begin{array}{l}\text { Postoperative } \\
\text { day } 1\end{array}$ \\
\hline Shoman et al. [11] & 30 versus 30 & 54 & 67 & NasoPore & Merocel & NA & $\begin{array}{l}\text { Postoperative } \\
\text { day } 7\end{array}$ \\
\hline
\end{tabular}

Abs absorbable nasal packing material, $C M C$ carboxymethylated cellulose, NA data not available, Nonabs nonabsorbable nasal packing material, PVA polyvinyl alcohol

${ }^{a}$ Cotton gauze placed in a latex glove finger

and NasoPore [11] were used in one study each. Regarding nonabsorbable nasal packing material, Merocel was used in three studies [8, 11, 15] while polyvinyl alcohol sponges [12] and routine nasal packing (cotton gauze placed in a latex glove finger) [13] were used in one study each. Four of the five studies $[8,12,13,15]$ reported on postoperative treatments, all of which involved administration of various antibiotics. Three studies $[8,11,13]$ reported on the time to packing removal, which ranged from 1 to 7 days.

Study outcomes

The prevalence of synechia was reported in three studies $[8,12,13]$ and ranged from 4.6 to $8.0 \%$ in the absorbable 
Table 2 Summary of outcomes for studies included in the systematic review

\begin{tabular}{|c|c|c|c|c|c|c|}
\hline \multirow[t]{2}{*}{ References } & \multicolumn{6}{|l|}{ Abs versus nonabs } \\
\hline & Synechia & $\begin{array}{l}\text { Postoperative } \\
\text { bleeding }\end{array}$ & $\begin{array}{l}\text { Postoperative } \\
\text { pain }\end{array}$ & $\begin{array}{l}\text { Postoperative } \\
\text { edema }\end{array}$ & $\begin{array}{l}\text { Bleeding on } \\
\text { packing removal }\end{array}$ & $\begin{array}{l}\text { Pain on packing } \\
\text { removal }\end{array}$ \\
\hline Cho et al. [15] & NA & NA & NA & NA & $59 \%$ versus $91 \%$ & $\begin{array}{c}1.01 \pm 0.16 \text { versus } \\
2.37 \pm 0.19^{\mathrm{a}}\end{array}$ \\
\hline Miller et al. [8] & $\begin{array}{l}8.0 \text { versus } 8.0 \% \\
(8 \text { weeks })\end{array}$ & NA & NA & $\begin{array}{l}0.70 \pm 0.45 \text { versus } \\
0.71 \pm 0.45 \\
(8 \text { weeks })^{\mathrm{f}}\end{array}$ & NA & NA \\
\hline Berlucchi et al. [12] & $\begin{array}{l}4.6 \text { versus } 29.7 \% \\
\text { (12 weeks) }\end{array}$ & NA & NA & 43.2 versus $58.4 \%$ & NA & NA \\
\hline Szczygielski et al. [13] & $\begin{array}{l}6.7 \text { versus } 35.7 \% \\
(8 \text { weeks })\end{array}$ & $\begin{array}{l}13.3 \% \text { versus } \\
6.7 \%\end{array}$ & $\begin{array}{l}5.5(3-9) \text { versus } \\
0.962(0-4) \\
(24 \mathrm{~h})^{\mathrm{b}}\end{array}$ & NA & NA & NA \\
\hline Shoman et al. [11] & NA & $\begin{array}{l}3.67 \pm 2.45 \\
\text { versus } \\
3.44 \pm 2.01 \\
(1 \text { st week })^{\mathrm{d}}\end{array}$ & 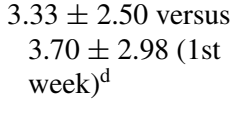 & 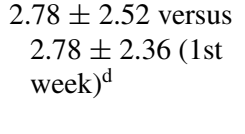 & $\begin{array}{c}0.90 \pm 0.55 \text { versus } \\
0.83 \pm 0.53^{\mathrm{e}}\end{array}$ & $\begin{array}{c}4.03 \pm 2.80 \text { versus } \\
3.97 \pm 2.72^{\mathrm{d}}\end{array}$ \\
\hline
\end{tabular}

Abs absorbable nasal packing material, Nonabs nonabsorbable nasal packing material, NA data not available, VAS visual analog scale

${ }^{\mathrm{a}}$ Five-point scale ranging from 0 to 4 , where $0=$ no pain and $4=$ worst pain imaginable; ${ }^{\mathrm{b}}$ VAS score ranging from 0 to 10 , where $0=$ no pain and $10=$ worst pain imaginable; ${ }^{\mathrm{c}}$ pain greater than 4 on VAS; ${ }^{\mathrm{d}}$ subjective score ranging from 0 to 10 , where $0=$ no bleeding/pain/edema and $10=$ maximal bleeding/pain/edema; ${ }^{\mathrm{e}}$ objective grade ranging from 0 to 3 , where $0=$ no bleeding and $3=$ severe bleeding requiring repacking;

${ }^{\mathrm{f}}$ blinded edema score ranging from 0 to 3 , where $0=$ no visible mucosal edema and $3=$ frank polyposis

packing groups and from 8.0 to $35.7 \%$ in the nonabsorbable packing groups. The duration of follow-up for monitoring of postoperative synechia was 8 weeks in two studies $[8,13]$ and 12 weeks in one study [12]. Postoperative bleeding data were reported in two studies [11,13], both of which found decreased bleeding in the absorbable group compared with the nonabsorbable group. Likewise, postoperative pain data were reported in the same two studies, one of which found that pain was considerable less in the absorbable group [13], whereas the other found that pain was less in the nonabsorbable group [11]. Three studies reported results on postoperative edema $[8,11,12]$. Two of these studies $[8,11]$ found no clear between-group differences in edema, whereas the other [12] found that edema was less pronounced in the absorbable group compared with the nonabsorbable group. Two studies [11, 15] each reported on bleeding and pain on packing removal. One study [15] found that pain and bleeding were both markedly reduced in the absorbable group compared with the nonabsorbable group, whereas the other study [11] found that pain and bleeding were similar between groups. The timing of the aforementioned assessments varied between studies (see Table 2).

\section{Quality assessment}

The quality of the studies included in the systematic review was assessed as highlighted in Table 3. Comprehensive information was not available for all studies [8, 13], and outcome assessor, care provider, and/or patient blinding did not occur in several studies $[8,11,12]$. Otherwise, the studies generally had characteristics consistent with being high-quality trials. Of note, aside from not including an intention-to-treat analysis, the study reported by Cho et al. [15] met all of the quality criteria.

\section{Meta-analysis of postoperative synechia}

Two studies $[8,12]$ were included in the meta-analysis of synechia, the results of which are summarized in Fig. 2. There was significant heterogeneity between the two studies for this outcome $\left(Q=3.492, I^{2}=71.37 \%, P=0.062\right)$; therefore, a random-effects model of analysis was used. The combined OR for postoperative synechia did not significantly favor absorbable nasal packing over nonabsorbable nasal packing or vice versa $(P=0.308)$.

Note: meta-analysis of the other postoperative outcomes was not possible due to significance between study heterogeneity.

\section{Discussion}

To our knowledge, this is the first systematic review/ meta-analysis to compare outcomes (including efficacy as indicated by postoperative synechia) of absorbable versus nonabsorbable nasal packing after FESS for the treatment of chronic rhinosinusitis. A total of five randomized 


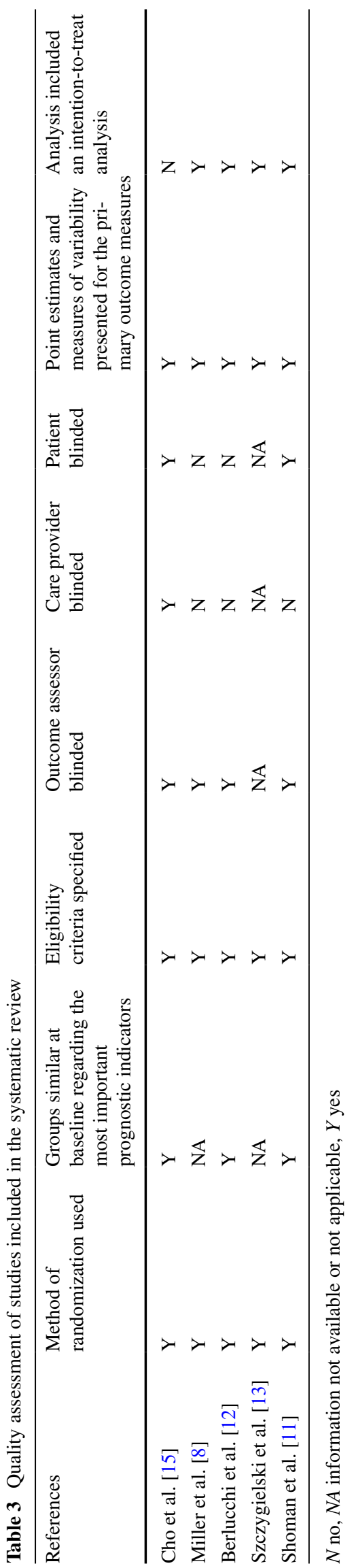

clinical trials, involving 241 nasal cavities in each treatment arm, met the criteria for inclusion in the systematic review. There was considerable variability in characteristics between studies, in particular, regarding the type of nasal packing material used. Postoperative bleeding was less with absorbable packing, whereas there were no betweengroup differences or consistent findings with regard to postoperative pain and edema, and pain and bleeding on packing removal. Of note, our meta-analysis, which included the findings from two studies, revealed that the incidence of postoperative synechia was not significantly reduced by absorbable compared with nonabsorbable nasal packing.

As already noted, our meta-analysis of results from randomized clinical trials revealed that absorbable nasal packing was not associated with a significantly lower risk of synechia after FESS for chronic rhinosinusitis compared with nonabsorbable nasal packing. Of the studies included in the systematic review part of the study, Szczygielski et al. [13] also reported on rates of synechia within 8 weeks of surgery and found a markedly lower rate among patients who received absorbable packing. Likewise, in a study not eligible for inclusion in our systematic review/metaanalysis, Hu et al. [16] found that there was a reduced rate of postoperative synechia among patients who received absorbable nasal packing (Meropack) compared with those who received no packing. In contrast, in a prospective, nonrandomized study, Baumann et al. [9] found little difference in the rate of postoperative synechia between patients who received absorbable (FloSeal) and nonabsorbable (Merocel) nasal packing. Several other studies have also failed to demonstrate any benefit of packing with CMC compared with no packing or nonabsorbable packing for reducing postoperative synechia $[17,18]$. The disparate findings between studies clearly reflect the lack of homogeneity, most notably in the type of absorbable packing material used. Unfortunately, this lack of homogeneity restricted our ability to make any definitive conclusions. The variability in synechia outcomes between studies does, however, suggest that different types of absorbable packing materials are not created equal when it comes to reducing postoperative synechia. Clearly, further randomized trials are needed to directly compare the efficacy of different absorbable packing materials for reducing synechia after FESS for the treatment of chronic rhinosinusitis.

Only two studies included in our systematic review provided data on postoperative bleeding; however, both of these studies found decreased bleeding with absorbable packing. The findings from several previous studies also suggest that packing with absorbable material (Meropack, Gelfoam) reduces postoperative bleeding compared with no packing [16, 19]. Further, Jameson et al. [20] have also reported decreased postoperative bleeding after FESS in nasal passages packed with absorbable (FloSeal) compared 


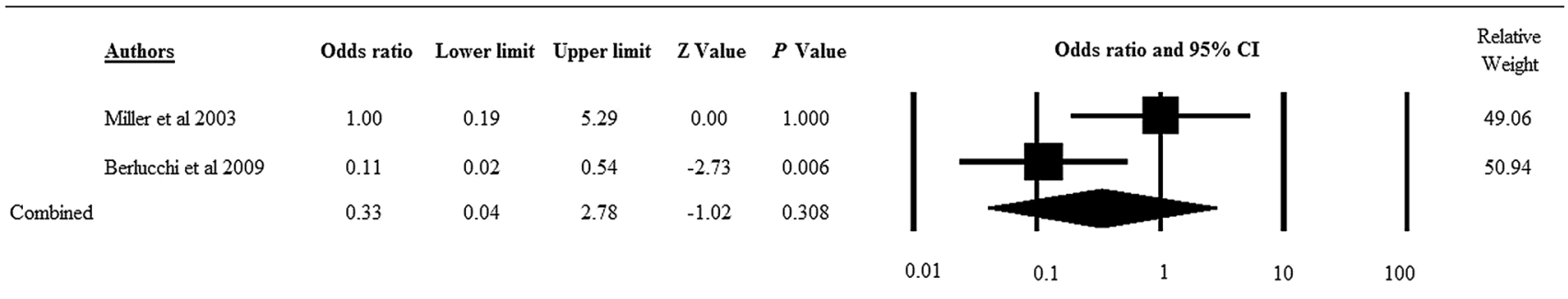

Favors absorbable packing Favors nonabsorbable packing

Fig. 2 Forest plot showing OR for postoperative synechia after functional endoscopic sinus surgery with absorbable versus nonabsorbable nasal packing for the treatment of chronic rhinosinusitis. Data are

with nonabsorbable packing. In contrast, several other studies have found no difference in postoperative bleeding with absorbable (NasoPore, CMC) versus nonabsorbable or no nasal packing $[11,21]$. As with postoperative synechia, the lack of homogeneity between studies may explain the disparate findings. Additional randomized trials are needed to further investigate the efficacy of absorbable versus nonabsorbable nasal packing for preventing bleeding after FESS for the treatment of chronic rhinosinusitis.

In addition to postoperative synechia and bleeding, we also examined other outcomes after FESS, including postoperative edema and pain, and bleeding and pain on removal of packing. Unsurprisingly, there was again a lack of consistency in these results between studies, although it should be noted that the study reported by Cho et al. [15], which had the most number of patients and was the highest quality randomized controlled trial included (according to our assessment), did reveal markedly less bleeding and pain on removal of absorbable compared with nonabsorbable nasal packing.

Our study has a number of limitations that must be acknowledged. Firstly, both the type of packing material used and the duration of follow-up were different between several studies. This markedly restricted our ability to perform meta-analyses of results. Secondly, our analyses did not take into account other important factors that may have biased the study findings (and indeed our meta-analysis), including indicators of packing efficacy, such as postoperative infection and edema granulation, associated pathologies, such as nasal polyps, aspirin sensitivity, perioperative treatment, postoperative debridement, smoking history. Thirdly, we chose not to assess patient satisfaction as an outcome measure. Clearly, this is a very important consideration when evaluating the effectiveness of any treatment; however, we feel it is more important to conclusively determine which means of nasal packing is most clinically effective before considering patient satisfaction. We do note, however, that presented as OR with $95 \%$ CI. Heterogeneity test results: $Q=3.492$, $d f=1, P=0.062, I^{2}=71.37 \%$

the results from a previous randomized controlled trial (not eligible for inclusion in our systematic review/metaanalysis) suggest that the majority of patients prefer absorbable nasal packing material (specifically MeroGel) over nonabsorbable material [10]. Fourthly, our metaanalysis only included a relatively small number of studies, thus limiting the power of analysis. Finally, we were not able to perform any analyses regarding the different types of FESS due to the lack of data/sufficiently detailed methodological descriptions.

The results of our systematic review and meta-analysis do not allow us to make any definitive conclusions regarding outcomes (including efficacy as indicated by the incidence of synechia) for the comparison of absorbable versus nonabsorbable nasal packing material after FESS. Clearly, there is some evidence to support the notion that absorbable packing may be superior to nonabsorbable packing; however, the distinct lack of homogeneity between studies reported in the current literature (particularly in the type of absorbable nasal packing material used) is a major limiting factor moving forward. Lack of homogeneity aside, our systematic review also highlights the fact that there is a scarcity of data available from high-quality randomized trials on the efficacy of absorbable versus nonabsorbable packing after FESS. Additional randomized controlled trials are needed, not only to provide more definitive information on the absorbable versus nonabsorbable packing debate, but also to compare the efficacy of different types of absorbable packing materials. We hope this report will help spur such trials.

\section{Acknowledgments None.}

Conflict of interest None declared.

Open Access This article is distributed under the terms of the Creative Commons Attribution License which permits any use, distribution, and reproduction in any medium, provided the original author(s) and the source are credited. 


\section{References}

1. Benninger MS, Ferguson BJ, Hadley JA, Hamilos DL, Jacobs M, Kennedy DW, Lanza DC, Marple BF, Osguthorpe JD, Stankiewicz JA, Anon J, Denneny J, Emanuel I, Levine H (2003) Adult chronic rhinosinusitis: definitions, diagnosis, epidemiology, and pathophysiology. Otolaryngol Head Neck Surg 129:S1-S32

2. Welch KC, Stankiewicz JA (2009) A contemporary review of endoscopic sinus surgery: techniques, tools, and outcomes. Laryngoscope 119:2258-2268

3. Khalid AN, Quraishi SA, Kennedy DW (2004) Long-term quality of life measures after functional endoscopic sinus surgery. Am J Rhinol 18:131-136

4. Govindaraj S, Adappa ND, Kennedy DW (2010) Endoscopic sinus surgery: evolution and technical innovations. J Laryngol Otol 124:242-250

5. Palmer O, Moche JA, Matthews S (2012) Endoscopic surgery of the nose and paranasal sinus. Oral Maxillofacc Surg Clin North Am 24:275-283

6. Soler ZM, Mace J, Smith TL (2008) Symptom-based presentation of chronic rhinosinusitis and symptom-specific outcomes after endoscopic sinus surgery. Am J Rhinol 22:297-301

7. Tan BK, Chandra RK (2010) Postoperative prevention and treatment of complications after sinus surgery. Otolaryngol Clin North Am 43:769-779

8. Miller RS, Steward DL, Tami TA, Sillars MJ, Seiden AM, Shete M, Paskowski C, Welge J (2003) The clinical effects of hyaluronic acid ester nasal dressing (Merogel) on intranasal wound healing after functional endoscopic sinus surgery. Otolaryngol Head Neck Surg 128:862-869

9. Baumann A, Caversaccio M (2003) Hemostasis in endoscopic sinus surgery using a specific gelatin-thrombin based agent (FloSeal). Rhinology 41:244-249

10. Franklin JH, Wright ED (2007) Randomized, controlled, study of absorbable nasal packing on outcomes of surgical treatment of rhinosinusitis with polyposis. Am J Rhinol 21:214-217

11. Shoman N, Gheriani H, Flamer D, Javer A (2009) Prospective, double-blind, randomized trial evaluating patient satisfaction, bleeding, and wound healing using biodegradable synthetic polyurethane foam (NasoPore) as a middle meatal spacer in functional endoscopic sinus surgery. J Otolaryngol Head Neck Surg 38:112-118

12. Berlucchi M, Castelnuovo P, Vincenzi A, Morra B, Pasquini E (2009) Endoscopic outcomes of resorbable nasal packing after functional endoscopic sinus surgery: a multicenter prospective randomized controlled study. Eur Arch Otorhinolaryngol 266:839-845

13. Szczygielski K, Rapiejko P, Wojdas A, Jurkiewicz D (2010) Use of CMC foam sinus dressing in FESS. Eur Arch Otorhinolaryngol 267:537-540

14. Wormald PJ, Boustred RN, Le T, Hawke L, Sacks R (2006) A prospective single-blind randomized controlled study of use of hyaluronic acid nasal packs in patients after endoscopic sinus surgery. Am J Rhinol 20:7-10

15. Cho KS, Shin SK, Lee JH, Kim JY, Koo SK, Kim YW, Kim MJ, Roh HJ (2013) The efficacy of Cutanplast nasal packing after endoscopic sinus surgery: a prospective, randomized, controlled trial. Laryngoscope 123:564-568

16. Hu KH, Lin KN, Li WT, Huang HM (2008) Effects of Meropack in the middle meatus after functional endoscopic sinus surgery in children with chronic sinusitis. Int J Pediatr Otorhinolaryngol 72:1535-1540

17. Leunig A, Betz CS, Siedek V, Kastl KG (2009) CMC packing in functional endoscopic sinus surgery: does it affect patient comfort? Rhinology 47:36-40

18. Kastl KG, Betz CS, Siedek V, Leunig A (2009) Effect of carboxymethylcellulose nasal packing on wound healing after functional endoscopic sinus surgery. Am J Rhinol Allergy 23:80-84

19. Wee JH, Lee CH, Rhee CS, Kim JW (2012) Comparison between Gelfoam packing and no packing after endoscopic sinus surgery in the same patients. Eur Arch Otorhinolaryngol 269:897-903

20. Jameson M, Gross CW, Kountakis SE (2006) FloSeal use in endoscopic sinus surgery: effect on postoperative bleeding and synechiae formation. Am J Otolaryngol 27:86-90

21. Kastl KG, Betz CS, Siedek V, Leunig A (2009) Control of bleeding following functional endoscopic sinus surgery using carboxy-methylated cellulose packing. Eur Arch Otorhinolaryngol 266:1239-1243 